\title{
Are high-viscosity glass-ionomer cements inferior to silver amalgam as restorative materials for permanent posterior teeth? A Bayesian analysis
}

\author{
Steffen Mickenautsch
}

\begin{abstract}
Background: To develop a synthesis within a Bayesian probability framework of previously established evidence, in order to derive an overall conclusion about the hypothesis (H1): 'High-viscosity glass-ionomer cements (HVGIC) are inferior to silver amalgam as (load bearing) restorative materials for permanent posterior teeth'.

Methods: Following Bayesian method, the prior Odds that $\mathrm{H} 1$ is true (established from past uncontrolled clinical longitudinal and laboratory trials), the Likelihood Ratio incorporating new evidence (established from recent meta-epidemiological studies and systematic reviews of controlled clinical trials), as well as the posterior hypothesis Odds in view of the new evidence, were calculated.

Results: The prior Odds that HVGICs are clinically inferior to amalgam as restorative materials in posterior permanent teeth in relation to the hypothesis that this is not so was 1.12 to 1 . The Likelihood Ratio based on new evidence in favor the hypothesis was zero and the subsequent posterior Odds 0 to 1. Therefore, based on the new evidence, the Odds that HVGICs are clinically inferior to amalgam as restorative materials in posterior permanent teeth degreased from 1.12 to zero.

Conclusion: The current evidence suggests lack of support for the hypothesis that high-viscosity glass-ionomer cements are inferior to silver amalgam as restorative materials for permanent posterior teeth. Should future research to this topic uphold the current findings, a wider range of clinical benefits for both patient and care provider, beyond appropriate restoration longevity for placing HVGIC based restorations may apply.
\end{abstract}

Keywords: Amalgam, High-viscosity glass-ionomer, Posterior teeth restoration, Bayesian probability

\section{Background}

The term 'high-viscosity' or 'high-viscous glass-ionomer cement' (HVGIC) has emerged within the scientific dental literature and is related in clinical studies specifically to the products Fuji IX (GC Corporation, Japan) or Ketac Molar (3 M ESPE, Germany) [1]. A definition of HVGICs in line with chemical characteristics such as the powder liquid ratio or its compressive strength in comparison to other chemically cured glass-ionomers appears difficult due to contradictive in-vitro evidence [1]. However, HVGICs appear distinct from other (low) viscosity glassionomers (including Cermets) in their comparative clinical

Correspondence: neem@global.co.za

SYSTEM Initiative, Department of Community Dentistry, Faculty of Health

Sciences, University of the Witwatersrand, 7 York Rd., Parktown/Johannesburg 2193, South Africa survival rate to that of conventional amalgam restorations. Meta-analysis results indicate a survival rate for HVGIC (Fuji IX; Ketac Molar) tooth restorations similar to that of amalgam but show significantly lower survival rates for "low-viscosity" GICs (Chelon Silver (= Cermet); Chem Fil; Fuji II) than for amalgam [2].

Glass ionomers, such as HVGICs, are reported to adhere primarily via calcium bonds to the mineral content of teeth [3] and thus provide an adaptive seal. As HVGIC's leach fluoride ions into the adjacent tooth tissue, these materials are assumed to be capable of slowing the progression of carious lesions [4]. For these reasons, HVGICs are expected to be ideally suited for the management of dental caries. Additionally, they may simplify the tooth restorative procedure and enable the dentine-pulp complex to react against the caries process [5]. 
During a systematic review of clinical controlled trials, the survival rate of HVGIC restorations, placed using the atraumatic restorative treatment approach, in permanent posterior teeth in comparison to conventionally placed silver amalgam has been established [6]. This systematic review was further updated [7] and the detailed results, including additional results from Chinese trials, published by the authors $[8,9]$. All published reports of this systematic review indicated no differences between HVGIC and amalgam, beyond the play of chance $(p>0.05)$ in the permanent dentition after four and six years for single and multiple surface tooth restorations, respectively, and no differences after three years for single and multiple surface restorations in primary teeth $[6,7,10]$. The results from Chinese trials were confirmatory of these findings [8].

The systematic review findings are in disagreement with results from one comprehensive, non-systematic literature review by Manhart et al. [11]. The conclusion of this review was that glass-ionomers were generally inferior to amalgam for placing restorations in posterior teeth. This review extracted the annual failure rates of different restoration types, including amalgam and glass-ionomers, from mainly clinical cross-sectional and uncontrolled clinical longitudinal studies and calculated their mean with standard deviation and median values for naïve-indirect comparison by use of analysis of variances (ANOVA) [11].

Against this background, an empirical metaepidemiological study was conducted in order to investigate whether trends and performance differences between conventional amalgam and direct HVGIC restorations in posterior teeth can be correctly inferred through naïve-indirect comparison of failure rates from uncontrolled longitudinal clinical studies [1]. Based on the study's result, the null-hypothesis that trends and performance differences inferred from naive-indirect-indirect comparison based on evidence from clinical uncontrolled longitudinal studies and from direct comparisons based on randomised control trial (RCT) evidence, concerning conventional amalgam versus direct HVGIC restorations, have similar direction and magnitude, was rejected. It was further concluded that naïve-indirect comparison of failure rates from uncontrolled longitudinal clinical studies are unsuitable for clinical inference, particularly in regard to the clinical HVGIC efficacy for placing direct tooth restorations.

In addition to uncontrolled longitudinal clinical studies, laboratory trial results are sometimes used as basis for clinical inference and recommendations for daily dental practice. Based on laboratory evidence, glassionomers are traditionally considered as unsuitable for clinical use as a permanent filling material in the posterior dentition due to in-vitro measured poor mechanical properties [12, 13]. Specifically, in-vitro measured low material strength and wear resistance have been stated as reasons why glass-ionomers cannot rival amalgam as truly universal posterior restorative material [14].

A meta-epidemiological study was conducted in order to test the null-hypotheses whether the results from laboratory trials concerning HVGICs versus amalgam indicate similar effect direction and magnitude as results from clinical controlled trials concerning HVGICs versus amalgam restorations placed in permanent posterior teeth [10]. The results of this study showed that the effect direction and magnitude are not similar and that, similar to the investigation concerning the naïve-indirect-indirect comparison method based on evidence from clinical uncontrolled longitudinal studies [1], the nullhypotheses had to be rejected. In addition, this study raised reasons for doubt regarding the general suitability of laboratory trials for clinical inference [10].

After the conduct and reporting of systematic review $[8,9]$ and meta-epidemiological study $[1,10]$ results regarding the clinical efficacy of HVGICs versus amalgam as the current restorative gold standard, an integrative analysis of all evidence combined to the topic has still been missing. For this reason, the aim of this study was to present a synthesis of previously established evidence within a Bayesian framework, in order to derive an overall conclusion about the Odds in regard to the hypothesis that HVGIC's are inferior to silver amalgam as restorative materials for permanent posterior teeth.

\section{Method}

\section{Bayesian framework}

Two hypotheses were generated:

(i) H1: HVGICs are clinically inferior to amalgam as restorative materials in posterior permanent teeth;

(ii) H2: HVGICs are clinically not inferior to amalgam as restorative materials in posterior permanent teeth.

Following Bayesian method, the prior Odds of hypothesis $\mathrm{H} 1$ (relative to $\mathrm{H} 2$ ) based on previous evidence, the Likelihood Ratio incorporating new evidence, as well as the posterior Odds of hypothesis $\mathrm{H} 1$ (relative to $\mathrm{H} 2$ ) in view of the new evidence, were calculated.

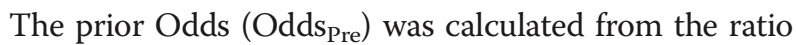
of the probability that $\mathrm{H} 1$ is correct, $\mathrm{P}(\mathrm{H} 1)$, to the probability that $\mathrm{H} 2$ is correct, $\mathrm{P}(\mathrm{H} 2)$, i.e.: $\operatorname{Odds}_{\text {Pre }}=\mathrm{P}(\mathrm{H} 1)$ / $\mathrm{P}(\mathrm{H} 2)$; with $\mathrm{P}(\mathrm{H} 2)=1-\mathrm{P}(\mathrm{H} 1)$. All probabilities were calculated as the ratio of the number of hypothesis supporting events (n) to the total number of evaluated events (N) based on previous evidence from naïve-indirect-indirect comparison of results from clinical uncontrolled longitudinal trials and from laboratory trials.

The Likelihood Ratio (LR) was calculated from the ratio of the probability of $\mathrm{H} 1$ according to new evidence, $\mathrm{P}(\mathrm{E} \mid \mathrm{H} 1)$ to the probability of $\mathrm{H} 2$ according to 
new evidence, $\mathrm{P}(\mathrm{E} \mid \mathrm{H} 2)$, i.e.: $\mathrm{LR}=\mathrm{P}_{\mathrm{n}}(\mathrm{E} \mid \mathrm{H} 1) / \mathrm{P}_{\mathrm{n}}(\mathrm{E} \mid \mathrm{H} 2) \times$ $\mathrm{P}_{\mathrm{n}+1}(\mathrm{E} \mid \mathrm{H} 1) / \mathrm{P}_{\mathrm{n}+1}(\mathrm{E} \mid \mathrm{H} 2)$. The new evidence (E) was established from empirical study results (labelled as 'Evidence 1') [1, 10], and systematic review evidence (labelled as 'Evidence 2') [8, 9].

The posterior Odds (Odds Post $)$ were calculated by multiplication of the prior Odds with the Likelihood Ratio.

An assessment of sufficient statistical power due to sample size was conducted. If sample sizes were too small the event results would lack sufficient statistical power in order to detect meaningful differences (beyond the play of chance) between effect estimates and thus would erroneously favor hypothesis H2. For this reason, all extracted events were analyzed for sufficient statistical power.

The assessment was based on the following assumptions:

(i) Risk of type I error (risk of falsely detecting a difference), $\alpha=5 \%$;

(ii) Risk of type II error (risk of not detecting a true difference), $\beta=20 \%$;

(iii) Power to detect a 10-percentage point difference in the failure rate between HVGIC and amalgam restorations.

The assumption of 10-percentage point difference in the failure rate was chosen in line with the work by Taifour et al. [15] concerning placed HVGIC restorations in permanent teeth versus amalgam. The analysis was conducted by calculating the needed sample size per group $\left(\mathrm{N}_{\mathrm{P}}\right)$ with an assumed test group (HVGIC) event rate $\left(\mathrm{P}_{1}\right.$ in \%) that is 10 percentage points higher than that of the control group $\left(\mathrm{P}_{2}\right.$ in \% /Amalgam) using the formula by Pocock [16]:

$$
\begin{aligned}
& \text { (1) } \mathrm{N}_{\mathrm{P}}=\left\{\left[\mathrm{P}_{1}\left(100-\mathrm{P}_{1}\right)+\mathrm{P}_{2}\left(100-\mathrm{P}_{2}\right)\right] /\right. \\
& \left.\left(\mathrm{P}_{2}-\mathrm{P}_{1}\right)^{2}\right\} \times f(\alpha, \beta) \text {, with: } \\
& \text { a. } \mathrm{P}_{1}=\mathrm{P}_{2}+10 \% \\
& \text { b. Control group event rate }=\mathrm{n} / \mathrm{N} \\
& \text { c. } f(\alpha, \beta)=f(0.05,0.20)=7.9[16]
\end{aligned}
$$

The event rate of the control group $\left(\mathrm{P}_{2}\right)$ was calculated from the number of failed amalgam restorations (n) in relation to the total number of restorations evaluated $(\mathrm{N})$ that were extracted from the clinical trials.

Datasets with a combined sample size (test- and control group / $\mathrm{N}_{\mathrm{T}}$ ) that was lower than twice the needed sample size per group $\left(2 \mathrm{xN}_{\mathrm{P}}\right)$ were excluded from analysis. For datasets from Evidence 2 [8, 9], where more than one dataset per trial was reported, the next dataset with sufficient sample size and longest follow-up period was chosen. All datasets for sensitivity analyses are presented in Additional file 1: Table S1.

\section{Prior odds of hypothesis $\mathrm{H} 1$ relative to $\mathrm{H} 2$}

A total of 17 events were observed from naïve-indirect comparisons of clinical uncontrolled longitudinal trial results ${ }^{1}$ and from laboratory trial results [10]. The event outcome was reported as Odds ratio (OR) or Standardised Mean Difference (SMD) with 95 \% Confidence interval (CI) (Additional file 1: Table S1).

Events observed from naïve-indirect comparisons of clinical uncontrolled longitudinal trial results originated from two groups of trials: one group investigating HVIGICs and the other amalgam. All trials were identified through a systematic literature search in the PubMed/ Medline database (Date of search: September 25, 2012) following a simple, systematic search strategy, including the search terms: "atraumatic restorative treatment" for longitudinal studies investigating HVGIC and the string of MeSH search terms "Dental Amalgam"[Mesh] AND "Dental Restoration, Permanent"[Mesh] for longitudinal studies investigating amalgam. The search period was limited to publications from 2002/01/01 to 2012/09/25. Trial inclusion criteria were: (i) Prospective clinical onearm study (uncontrolled longitudinal study investigating either direct HVGIC or conventional amalgam restorations) or quasi-one-arm study (two-arm study that did not compare HVGIC with amalgam restorations, but included either HVGIC or amalgam as one of the study arms); (ii) Minimum 12-month follow-up period; (iii) Investigated cavity type Class I or II in permanent posterior teeth (Tunnel restorations not included); (iv) Publication language: English; (v) Study outcome: restoration failure [1].

Events observed from non-clinical, laboratory investigations originated from trials that established the material characteristics of HVGICs with silver amalgam as control. The trials were identified on basis of a systematic literature search (Dates of search: September 12 and 14, 2014), comprising a search of the databases: CENTRAL accessed via Cochrane Library; MEDLINE accessed via PubMed; Biomed Central; Database of Open Access Journals (DOAJ); IndMed; OpenSIGLE and Google Scholar. Trial inclusion criteria were: (i) Articles published in English; (ii) Full reports of prospective clinical controlled (including randomised control trials and non- randomised control trials) and laboratory trials (including: in-vitro; in-vivo on animal tissues); (iii) Head-to-head comparison of highviscosity glass-ionomers (HVGIC) versus amalgam; (iv) Longest follow-up period reported per trial; (v) Relevance to tooth restorations in posterior teeth of the permanent dentition; (vi) Computable data reported [10]. Further detailed information regarding both systematic literature searches have been presented elsewhere $[1,10]$.

Events with $95 \%$ Confidence intervals that indicated a statistically significant higher effect size in favour of amalgam were considered as evidence in support of hypothesis $\mathrm{H} 1\left(\mathrm{n}_{\mathrm{H} 1}\right)$ and events whose $95 \%$ Confidence 
intervals indicated no statistically significant difference between HVGICs and amalgam, as well as events that indicated a statistically significant higher effect size in favour of HVGIC were considered as evidence in support of hypothesis $\mathrm{H} 2\left(\mathrm{n}_{\mathrm{H} 2}\right)$. All events are presented in Additional file 1: Table S1. The prior Odds of hypothesis $\mathrm{H} 1$ relative to $\mathrm{H} 2$ were calculated using the following mathematical steps:

(2) $\mathrm{P}(\mathrm{H} 1)=\mathrm{n}_{\mathrm{H} 1} / \mathrm{N}$ and $\mathrm{P}(\mathrm{H} 2)=\mathrm{n}_{\mathrm{H} 2} / \mathrm{N}[1,10]$

(3) $\operatorname{Odds}_{\text {Pre }}=\mathrm{P}(\mathrm{H} 1) / \mathrm{P}(\mathrm{H} 2)$

\section{Likelihood Ratio of strength of evidence in favour of hypothesis $\mathrm{H} 1$ relative to hypothesis $\mathrm{H} 2$}

All studies concerning naïve-indirect-indirect comparison based on evidence from clinical uncontrolled longitudinal trials [1] and laboratory trial results [10], established only poor and unreliable bases for clinical inference. Therefore, the probabilities, derived from Evidence 1 were assumed to be equivocal for hypothesis $\mathrm{H} 1$ and $\mathrm{H} 2$, i.e.: $\mathrm{P}(\mathrm{H})=0.50$.

A total of three events related to restorations placed in posterior permanent teeth (Additional file 1: Table S1) were observed from RCTs. The trials were identified on basis of a systematic literature search up to January 2012 $[8,9]$ including the databases MEDLINE accessed via PubMed; CENTRAL accessed via Cochrane Library; Open access sources: Biomed Central, Database of Open Access Journals (DOAJ), OpenJ-Gate; Regional databases: Bibliografia Brasileira de Odontologia (BBO), Literatura Latino-Americana e do Caribe em Ciências da Saúde
(LILACS), IndMed, Sabinet, Scielo; Grey-Literature sources: Scirus (Medicine), OpenSIGLE, Google Scholar [9]; as well as Chinese Biomedical Literature Database (CBM), China National Knowledge Infrastructure (CNKI, formerly China Academic Journals), VIP Information and WanFang Data [8]. Further detailed information regarding the systematic literature search have been presented elsewhere $[8,9]$. Because the systematic review reported data at all follow-up intervals per trial, only events with the longest follow-up period per trial were selected for analysis, in order to avoid data duplication. Where available, results from meta-analyses were given selection priority over that of single datasets $[8,9]$. The result of each event was reported as Odds ratio (OR with $95 \% \mathrm{CI}$ ). Events whose $95 \%$ Confidence intervals indicated a statistically significant higher effect size in support of amalgam were considered as evidence in favour of hypothesis $\mathrm{H} 1\left(\mathrm{n}_{\mathrm{H} 1}\right)$ and events whose $95 \%$ Confidence intervals indicated no statistically significant difference between HVGICs and amalgam or indicated a statistically significant higher effect size in favour of HVGIC were considered as evidence in support of hypothesis $\mathrm{H} 2\left(\mathrm{n}_{\mathrm{H} 2}\right)$. The Likelihood Ratio of strength of evidence in support of hypothesis $\mathrm{H} 1$ relative to hypothesis $\mathrm{H} 2$ was calculated using the following steps:

(4) $\mathrm{P}_{1}\left(\mathrm{E}_{1} \mid \mathrm{H} 1\right)=$ assumed to be 0.50

(5) $\mathrm{P}_{2}\left(\mathrm{E}_{2} \mid \mathrm{H} 1\right)=\mathrm{n}_{\mathrm{H} 1} / \mathrm{N}_{2}$ and $\mathrm{P}_{2}\left(\mathrm{E}_{2} \mid \mathrm{H} 2\right)=\mathrm{n}_{\mathrm{H} 2} / \mathrm{N}_{2}$

(6) $\mathrm{LR}=\mathrm{P}_{1}\left(\mathrm{E}_{1} \mid \mathrm{H} 1\right) / \mathrm{P}_{1}\left(\mathrm{E}_{1} \mid \mathrm{H} 2\right) \times \mathrm{P}_{2}\left(\mathrm{E}_{2} \mid \mathrm{H} 1\right) / \mathrm{P}_{2}\left(\mathrm{E}_{2} \mid \mathrm{H} 2\right)$

\section{Results}

Figure 1 shows the sources of evidence that were included in the Bayesian analysis. Nine and eight out of 17

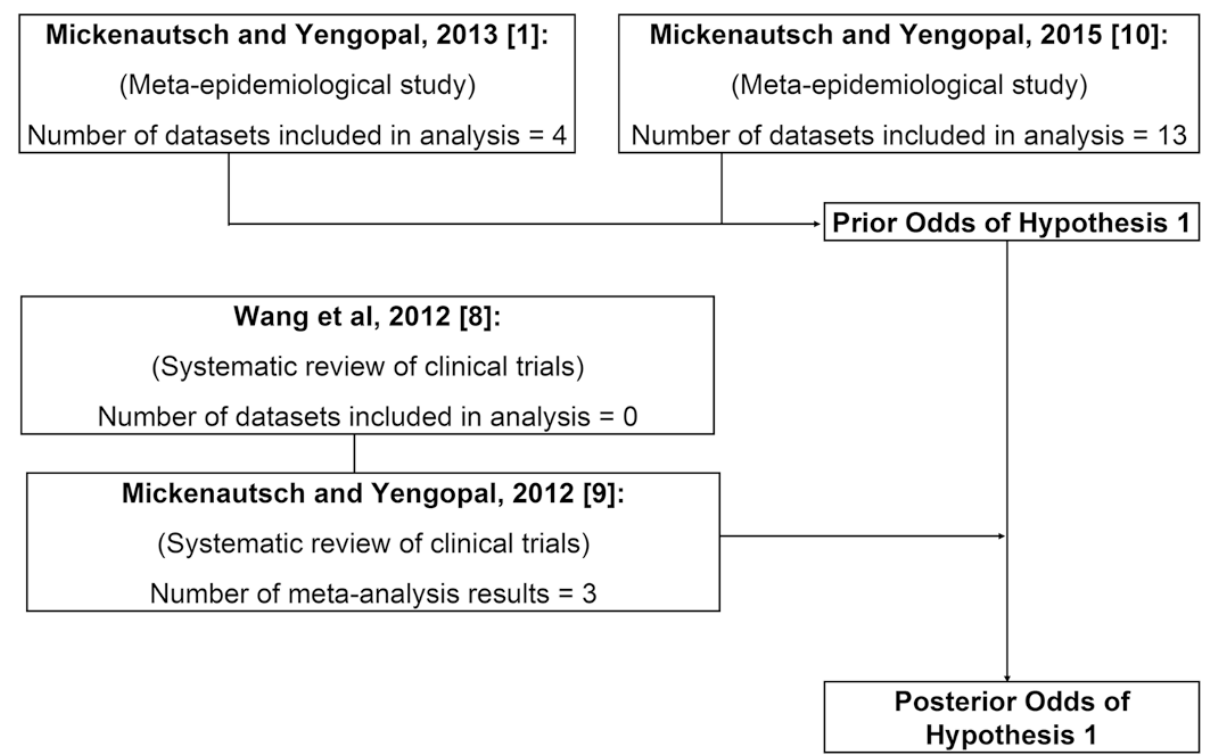

Fig. 1 Flow chart of evidence included in the Bayesian analysis. Number of meta-analysis results and datasets included in analysis, after assessment for sufficient statistical power 
events from uncontrolled clinical longitudinal and laboratory studies $(\mathrm{n} / \mathrm{N})$ were found in support of the hypothesis $\mathrm{H} 1$ and $\mathrm{H} 2$, respectively $[1,10]$. Therefore, the prior Odds (Odds $s_{\text {Pre }}$ ) that HVGICs are clinically inferior to amalgam as restorative materials in posterior permanent teeth (H1) in relation to the hypothesis that this is not so (H2) was 1.12 (Table 1).

New evidence was obtained from investigations concerning the suitability of naïve-indirect comparison of results from uncontrolled clinical longitudinal studies [1] and laboratory trials [10] for clinical inference. The results of both were found to be inconsistent with that of clinical randomised control trials (RCT) and thus were judged to provide only uncertain evidence for either hypothesis. For that reason, the probabilities, $\mathrm{P}(\mathrm{H})$, for hypothesis $\mathrm{H} 1$ and $\mathrm{H} 2$ based on Evidence 1 were estimated to be 0.50 . In addition, the evidence from a systematic review of clinical controlled trials was included (Evidence 2) $[8,9]$. In the systematic review report, a total of zero and three out three events from clinical control trials $(\mathrm{n} / \mathrm{N})$ were found in support of the hypothesis $\mathrm{H} 1$ and $\mathrm{H} 2$, respectively

Table 1 Bayesian probability analysis

\begin{tabular}{|c|c|c|}
\hline \multicolumn{3}{|l|}{ 1. Hypotheses } \\
\hline \multicolumn{2}{|c|}{$\begin{array}{l}\mathrm{H} 1 \text { : HVGICs are clinically inferior to } \\
\text { amalgam as restorative materials in } \\
\text { posterior permanent teeth }\end{array}$} & $\begin{array}{l}\mathrm{H} 2 \text { : HVGICS are clinically } \\
\text { not inferior to amalgam as } \\
\text { restorative materials } \\
\text { in posterior permanent teeth }\end{array}$ \\
\hline \multicolumn{3}{|c|}{ 2. Prior Odds of hypothesis $\mathrm{H} 1$ relative to $\mathrm{H} 2$} \\
\hline \multirow[t]{5}{*}{ a. Evidence } & \multicolumn{2}{|c|}{ Evidence $1[1,10]$} \\
\hline & \multicolumn{2}{|c|}{$P(H 1)=n_{H 1} / N=9$ out of $17=0.53$} \\
\hline & \multicolumn{2}{|c|}{$P(H 2)=n_{H 2} / N=8$ out of $17=0.47$} \\
\hline & \multicolumn{2}{|c|}{ Oddspre $=P(H 1) / P(H 2)$} \\
\hline & \multicolumn{2}{|c|}{ Oddspre $=0.53 / 0.47$} \\
\hline b. Oddspre & \multicolumn{2}{|c|}{$=1.12$} \\
\hline \multicolumn{3}{|c|}{$\begin{array}{l}\text { 3. Likelihood Ratio }(L R) \text { in support of hypothesis } H 1 \text { relative to } \\
\text { hypothesis } \mathrm{H} 2\end{array}$} \\
\hline \multirow[t]{8}{*}{ a. New Evidence } & \multicolumn{2}{|c|}{ Evidence $1[1,10]$} \\
\hline & \multicolumn{2}{|c|}{$P_{1}\left(E_{1} \mid H 1\right)=0.50$} \\
\hline & \multicolumn{2}{|c|}{$P_{1}\left(E_{1} \mid H 2\right)=0.50$} \\
\hline & \multicolumn{2}{|c|}{ Evidence $2[8,9]$} \\
\hline & \multicolumn{2}{|c|}{$\mathrm{P}_{2}\left(\mathrm{E}_{2} \mid \mathrm{H} 1\right)=\mathrm{n}_{\mathrm{H} 1} / \mathrm{N}_{3}=0$ out of $3=0$} \\
\hline & \multicolumn{2}{|c|}{$P_{2}\left(E_{2} \mid H 2\right)=n_{H 2} / N_{3}=3$ out of $3=1.00$} \\
\hline & \multicolumn{2}{|c|}{$\begin{array}{l}\mathrm{LR}=\mathrm{P}_{1}\left(\mathrm{E}_{1} \mid \mathrm{H} 1\right) / \mathrm{P}_{1}\left(\mathrm{E}_{1} \mid \mathrm{H} 2\right) \times \mathrm{P}_{2}\left(\mathrm{E}_{2} \mid \mathrm{H} 1\right) / \\
\mathrm{P}_{2}\left(\mathrm{E}_{2} \mid \mathrm{H} 2\right)\end{array}$} \\
\hline & \multicolumn{2}{|c|}{$L R=(0.50 / 0.50) \times(0 / 1.00)$} \\
\hline b. LR & \multicolumn{2}{|l|}{$=0$} \\
\hline \multicolumn{3}{|c|}{ 4. Posterior Odds of hypothesis $\mathrm{H} 1$ relative to $\mathrm{H} 2$} \\
\hline \multirow[t]{2}{*}{ a. Calculation } & \multicolumn{2}{|c|}{ Oddspost $_{1}=$ Oddspre $\times L R$} \\
\hline & \multicolumn{2}{|c|}{ Odds $_{\text {post }}=1.12 \times 0$} \\
\hline b. Oddspost & \multicolumn{2}{|l|}{$=0$} \\
\hline
\end{tabular}

(Evidence 2). Data of the three events was obtained from two meta-analyses and eight single datasets (Additional file 1: Table S1). Consequently, the calculated Likelihood Ratio (LR) was zero (Table 1).

Multiplication of the Likelihood Ratio (LR) with the prior Odds $\left(\right.$ Odds $_{\mathrm{Pre}}$ ) lead to the posterior Odds (OddsPost) that hypothesis $\mathrm{H} 1$ is true (relative to $\mathrm{H} 2$ ) to be zero. Therefore, based on the new evidence [1, 8-10], the Odds that HVGICs are clinically inferior to amalgam as restorative materials in posterior permanent teeth degreased from 1.12 to zero (Table 1). The results were graphically presented in Fig. 2.

Based on the applied criteria for sufficient statistical power $[15,16]$ the results of 22 single datasets from Evidence 1 and one meta-analysis and eight single datasets from Evidence 2 were excluded. The results from laboratory studies were all included, as these did not originate from clinical investigations (Additional file 1: Table S1).

\section{Discussion}

The aim of this study was to present a synthesis of previously established evidence, in order to derive an overall conclusion about the Odds in regard to the hypothesis that HVGIC's are inferior to silver amalgam as restorative materials for permanent posterior teeth. For this purpose, a Bayesian framework was used.

\section{Limitations of method}

The main objection to Bayesian analysis is that prior probabilities of hypotheses, i.e. before consideration of any evidence, were traditionally established from pure subjective assumptions [17]. Such assumption would have directly affected the prior Odds $\left(\operatorname{Odds}_{\text {Pre }}\right)$, which is used for calculation of the final analysis result $\left(\right.$ Odds $_{\text {Post }}=$ Odds $_{\text {Pre }} \times$ LR). Within the context of this study, no subjective assumptions were utilized, thus the objection to the use of Bayesian analysis in this study does not apply. Instead of subjective assumptions, prior probabilities were established from evidence that was identified through systematic literature search $[1,10]$. The results' limitation need to be considered in line with the limitations of the literature searches, which were discussed in details elsewhere $[1,10]$. These limitations were: both searches were restricted to English literature $[1,10]$, and one search used PubMed as the only database and only included literature listed during the period from $2002-2012$ [1].

In addition, the results are further limited by the internal validity of all clinical trials that were included in the meta-epidemiological studies $[1,10]$ and systematic reviews $[8,9]$. Trial validity assessment was included in both and judged as generally weak $[1,8-10]$.

The language restriction was justified on basis that treatment effect estimates from non-English studies are shown to be $16 \%$ more beneficial (Ratio of estimates 


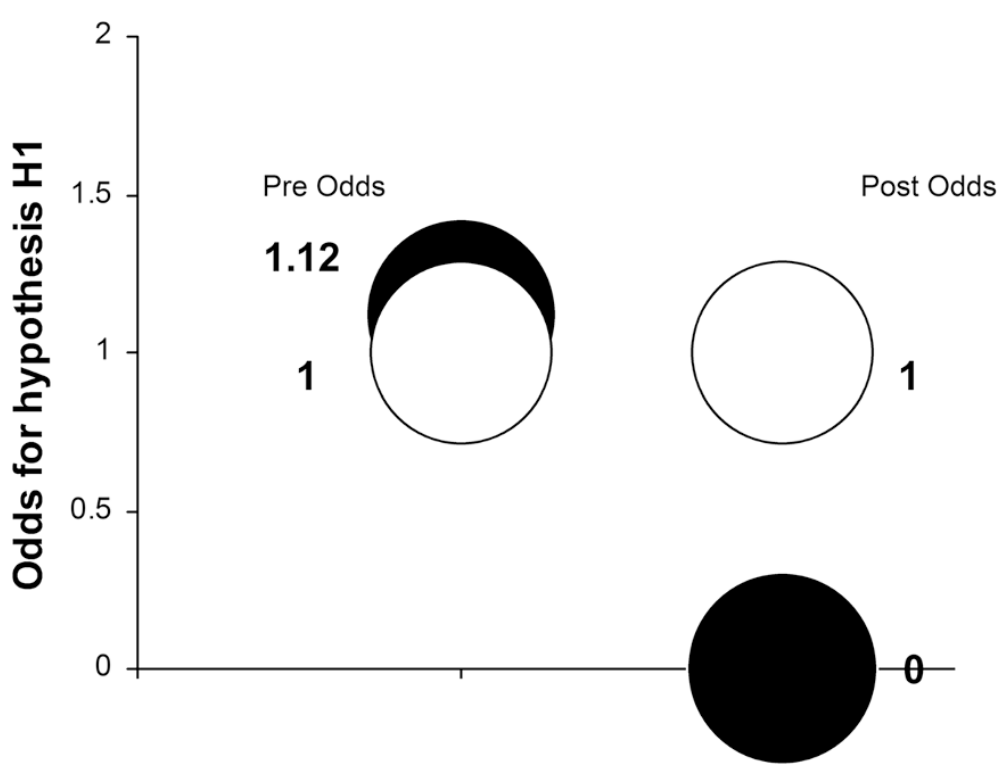

Fig. 2 Odds in support of hypothesis H1. The black circles' distance from the white circles on the vertical scale represent graphically the Odds for $\mathrm{H} 1$ in relation to $\mathrm{H} 2(=1.00)$

0.84; $95 \%$ CI: $0.74-0.97 ; p=0.011)$ than that of results published in English [18] and thus may introduce some level of overestimation. Thus excluding non-English trials from the systematic literature searches might in some cases render its results more conservative. In contrast, language restricted meta-analyses, compared to language inclusive meta-analyses did not differ in their effect size estimates (ROR 50.98; 95 \% CI: 0.811.17) [19]. For these reasons, the failure to include nonEnglish trials may not have biased the current results. While the search in one main database (PubMed) may have limited the results in one study [1] its 10-year publication limit may have reduced the risk of chronological bias as no RCTs that provided direct comparison between HVGIC and amalgam restorations (used as control group in that study) before that period could be identified.

Bayesian analysis by multiplication of probability ratios, $P_{n}(H 1) / P_{n}(H 2) \times P_{n+1}(H 1) / P_{n+1}(H 2)$, from different evidence sources is based on the assumption that these sources are independent from each other. Evidence $1[1,10]$ may not be regarded as strictly independent from Evidence $2[8,9]$, as the result of the latter served as control data for the former $[1,10]$. However, the results of both empirical studies let to a $50 / 50$ assumption in support for either hypothesis and rendered the product, $\mathrm{P}_{1}\left(\mathrm{E}_{1} \mid \mathrm{H} 1\right) / \mathrm{P}_{1}\left(\mathrm{E}_{1} \mid \mathrm{H} 1\right) \times \mathrm{P}_{2}\left(\mathrm{E}_{2} \mid \mathrm{H} 1\right)$ $/ \mathrm{P}_{2}\left(\mathrm{E}_{2} \mid \mathrm{H} 1\right)$ as 1.00 , thus did not affect mathematically the calculation of the Likelihood Ratio (Table 1).

Neither the results from possible naïve-indirect comparisons of uncontrolled laboratory trials nor the results from case reports or conclusions from non-systematic literature reviews (investigating either HVGICs or amalgam) were included in the Bayesian analysis. This may have reduced the Odds Pre - value but in turn will also have increased the validity of the prior Odds, as it may have reduced the level of bias risk and subjectivity that these types of study methods carry.

\section{Analysis results}

The Bayesian analysis results suggest that the posterior Odds for the hypothesis that HVGICs are inferior to silver amalgam as restorative materials for permanent posterior teeth are zero $(\mathrm{H} 1)$. Such results remain subject to revision on basis of future evidence that may or may not corroborate the current evidence. However, the current results from new evidence (E), identified through several systematic literature searches $[1,8-10]$ and under consideration of any prior evidence to this topic reduced the Odds to zero. The result can be explained on the basis that all data from Evidence 1 had to be considered invalid resulting in an equivocal $50 / 50$ probability that either hypothesis is true. Results from Evidence 2 indicated no event in support of hypothesis H1. Therefore, according to Bayesian calculus, the $\mathrm{P}_{2}\left(\mathrm{E}_{2} \mid \mathrm{H} 1\right)$ / $\mathrm{P}_{2}\left(\mathrm{E}_{2} \mid \mathrm{H} 2\right)$ quotient is derived by division of zero, thus rendering all subsequent multiplications with that quotient zero, as well.

If HVGIC restorations placed in permanent posterior teeth exhibit indeed no inferior clinical efficacy than silver amalgam (as still current gold standard for posterior tooth restorations) then their use as valid restorative treatment option may be justified. Such treatment option may have 
additional clinical benefit, besides its apparent lack of any higher restoration failure rates [6-9]: It has been reported that HVGICs are most suitable for tooth restoration after minimally-invasive cavity preparation, i.e. hand excavation of infected carious tooth tissue during the atraumatic restorative treatment approach [20]. Such restorative treatment that combines the use of HVGIC with cavity preparation by hand excavation has been clinically shown to generate smaller tooth restorations at the same clinical indications that would result in larger dental fillings, if amalgam had been placed by use of conventional cavity preparation with high-speed drilling instead [21]. The smaller HVGIC restorations have further been associated with less pain during placement in comparison to conventional amalgam restorations [22] and thus higher patient comfort during treatment with subsequent reduced levels of dental patient anxiety in adults [23]. A reduced level of patient anxiety may be associated with low operator stress levels, as high patient anxiety has been shown as one of the main stressors in daily dental practice [24]. In addition, HVGIC restorations, placed using the atraumatic restorative treatment approach, have been found to be more cost-effective than conventionally placed amalgam $[25,26]$ or composite restorations [26].

Against the background of such potential benefits and the Minamata Convention on Mercury's call for a phasedown approach to dental amalgam [27], HVGICs may be considered as possible amalgam alternative. However, the large number of excluded dataset and meta-analysis results is an indicator for remaining research gaps concerning HVGICs. These gaps were reported previously [28] and include a general lack of trials to many GIC related topics, as well as weak statistical power of existing trials due to small sample size. Such lack of statistical power was found to be further associated with wide confidence intervals of the effect estimates, which rendered trial results inconclusive. A particular need for more trials of suitable sample size was identified for establishing restoration longevity of HVGIC fillings placed, using hand-excavation following the atraumatic restorative treatment approach, in posterior permanent restorations in comparison to amalgam [28].

\section{Conclusions}

While the current evidence suggests lack of support for the hypothesis that high-viscosity glass-ionomer cements are inferior to silver amalgam as restorative materials for permanent posterior teeth, further studies are needed. Should further research uphold the current findings, a wider range of clinical benefits for both patient and care provider, beyond appropriate restoration longevity for placing HVGIC based restorations may apply.

\section{Additional file}

Additional file 1: Table S1. Extracted event data. (XLS 127 kb)

\section{Competing interests}

The author has been actively involved in the promotion; teaching and research of HVGIC based tooth restorations in the past (from 1998 to 2007).

\section{Authors' contributions}

SM developed the concept and outline and wrote this paper.

Received: 19 June 2015 Accepted: 6 October 2015

Published online: 08 October 2015

\section{References}

1. Mickenautsch S, Yengopal V. Direct contra naïve-indirect comparison of clinical failure rates between high-viscosity GIC and conventional amalgam restorations. An empirical study. PLoS One. 2013;8:e78397.

2. Frencken JE, Hof MA V 't, Van Amerongen WE, Holmgren CJ. Effectiveness of single-surface ART restorations in the permanent dentition: a meta-analysis. J Dent Res. 2004;83:120-3.

3. Yoshida Y, Van Meerbeek B, Nakayama Y, Snauwaert J, Hellemans L, Lambrechts $P$, et al. Evidence of chemical bonding at biomaterial-hard tissue interfaces. J Dent Res. 2000;79:709-71.

4. Mickenautsch S, Yengopal V, Leal SC, Oliveira LB, Bezerra AC, Bönecker M. Absence of carious lesions at margins of glass-ionomer and amalgam restorations: a meta- analysis. Eur J Paediatr Dent. 2009;10:41-6.

5. Ericson D, Kidd EAM, McComb D, Mjor I, Noack MJ. Minimally invasive dentistry - concept and techniques in cariology. Oral Health Prev Dent. 2003;1:59-72.

6. Mickenautsch S, Yengopal V, Banerjee A. Atraumatic restorative treatment versus amalgam restoration longevity: a systematic review. Clin Oral Investig. 2010;14:233-40.

7. Mickenautsch S, Yengopal V. Failure rate of high-viscosity GIC based ART compared to that of conventional amalgam restorations - evidence from a systematic review update. S Afr Dent J. 2012;67:329-31.

8. Wang $X$, Nie J, Cai $X$, Yengopal V, Mickenautsch S. Failure rate of atraumatic restorative treatment using high-viscosity glass-ionomer cement compared to conventional amalgam restorative treatment in primary and permanent teeth: a systematic review of Chinese trials. J Minim Interv Dent. 2012;5:377-415.

9. Mickenautsch S, Yengopal V. Failure rate of atraumatic restorative treatment using high-viscosity glass-ionomer cement compared to conventional amalgam restorative treatment in primary and permanent teeth: a systematic review update - III. J Minim Interv Dent. 2012;5:273-331.

10. Mickenautsch S, Yengopal V. Do laboratory results concerning high-viscosity glass ionomers versus amalgam for tooth restorations indicate similar effect direction and magnitude than that of controlled clinical trials? - A metaepidemiological study. PLoS One. 2015;10:e0132246.

11. Manhart J, Chen H, Hamm G, Hickel R. Buonocore Memorial Lecture. Review of the clinical survival of direct and indirect restorations in posterior teeth of the permanent dentition. Oper Dent. 2004;29:481-508.

12. Ilie N, Hickel R, Valceanu AS, Huth KC. Fracture toughness of dental restorative materials. Clin Oral Investig. 2012;16:489-98.

13. Ilie N, Hickel R. Mechanical behavior of glass ionomer cements as a function of loading condition and mixing procedure. Dent Mater J. 2007;26:526-33.

14. Naasan MA, Watson TF. Conventional glass ionomers as posterior restorations. A status report for the American Journal of Dentistry. Am J Dent. 1998;11:36-45.

15. Taifour D, Frencken JE, Beiruti N, van't Hof MA, Truin GJ, van Palenstein Helderman WH. Comparison between restorations in the permanent dentition produced by hand and rotary instrumentation-survival after 3 years. Community Dent Oral Epidemiol. 2003;31:122-8.

16. Pocock SJ. Clinical trials - A practical approach. John Wiley \& Sons Ltd., 1983; p. 125

17. Gelman A. Objections to Bayesian statistics. Bayes Analysis. 2008:3:445-50.

18. Jüni $P$, Holenstein F, Sterne J, Bartlett C, Egger M. Direction and impact of language bias in meta-analyses of controlled trials: empirical study. Int J Epidemiol. 2002;31:115-23. 
19. Moher D, Pham B, Klassen TP, Schulz KF, Berlin JA, Jadad AR, et al. What contributions do languages other than English make on the results of meta-analyses? J Clin Epidemiol. 2000;53:964-72.

20. Molina GF, Cabral RJ, Frencken JE. The ART approach: clinical aspects reviewed. J Appl Oral Sci. 2009;17(Suppl):89-98.

21. Rahimtoola S, van Amerongen E. Comparison of two tooth-saving preparation techniques for one-surface cavities. ASDC J Dent Child. 2002:69:16-26.

22. Rahimtoola $\mathrm{S}$, van Amerongen $\mathrm{E}$, Maher $\mathrm{R}$, Groen $\mathrm{H}$. Pain related to different ways of minimal intervention in the treatment of small caries lesions. ASDC J Dent Child. 2000;67:123-7.

23. Mickenautsch S, Frencken JE, van't HM. Atraumatic restorative treatment and dental anxiety in outpatients attending public oral health clinics in South Africa. J Public Health Dent. 2007;67:179-84.

24. Mickenautsch S, van't Hof MA, Frencken JE. Oral health service systems in Gauteng Province, South Africa. East Afr Med J. 2007;84:178-82.

25. Estupiñán-Day S, Milner T, Tellez M. Oral health of low income children: procedures for atraumatic restorative treatment (PRAT) - Final report. PAHO. 2006; Project number 091024: ATN/JF-7025-RG.

26. Mickenautsch S, Munshi I, Grossman ES. Comparative cost of ART and conventional treatment within a dental school clinic. S Afr Dent J. 2002;57:52-8.

27. FDI World Dental Federation. FDI policy statement on dental amalgam and the Minamata Convention on Mercury: adopted by the FDI General Assembly: 13 September 2014, New Delhi, India. Int Dent J. 2014;64:295-6.

28. Mickenautsch $\mathrm{S}$. Research gaps identified during systematic reviews of clinical trials: glass-ionomer cements. BMC Oral Health. 2012;12:18.

\section{Submit your next manuscript to BioMed Central and take full advantage of:}

- Convenient online submission

- Thorough peer review

- No space constraints or color figure charges

- Immediate publication on acceptance

- Inclusion in PubMed, CAS, Scopus and Google Scholar

- Research which is freely available for redistribution 